\title{
Engrailed-2 regulates genes related to vesicle formation and transport in cerebellar Purkinje cells
}

\author{
Martin I. Holst, ${ }^{\mathrm{a}}$ Christian Maercker,, ${ }^{\mathrm{b}, \mathrm{c}}$ Bogdan Pintea, ${ }^{\mathrm{a}}$ Marco Masseroli, ${ }^{\mathrm{d}}$ Christian Liebig, ${ }^{\mathrm{a}}$ Jakob Jankowski, \\ Andreas Miething, ${ }^{\mathrm{e}}$ Julia Martini, ${ }^{\text {a }}$ Beat Schwaller, ${ }^{\mathrm{f}}$ John Oberdick,,h \\ Karl Schilling, a and Stephan L. Baader ${ }^{\mathrm{a}, \mathrm{i}, *}$
}

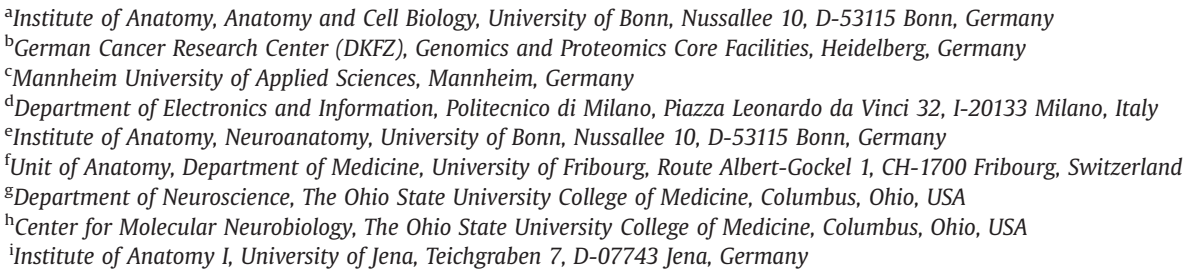

Keywords:

Cell polarity

Cerebellum

Cholecystokinin

Mtss $1 / \mathrm{mim}$

Polarity

Tetraspanin

Autism

\begin{abstract}
A B S T R A C T
Engrailed transcription factors regulate survival, cell fate decisions and axon pathfinding in central neurons. En-2 can also attenuate Purkinje cell (PC) maturation. Here, we use array analysis to scrutinize gene expression in developing PCs overexpressing Engrailed-2 (L7En-2). The majority (70\%) of regulated genes was found down-regulated in L7En-2 cerebella, consistent with the known repressive function of Engrailed2. Differential gene expression, verified by in situ hybridization or Western blotting, was particularly evident during the first postnatal week, when L7En-2 PCs display conspicuous deficits in dendritogenesis. Functional classification revealed clusters of genes linked to vesicle formation and transport. Consistently, Golgi stacks located at the axonal pole of wild type PC somata were rarely detected in L7En-2 PCs. In addition, long continuous stretches of endoplasmic reticulum typically found around the axonal pole of wild type PCs were less frequently observed in transgenic cells. Engrailed-2 might therefore orchestrate PC survival and process formation as a regulator of subcellular organization.
\end{abstract}

\section{Introduction}

Engrailed (En) is a homeodomain-containing transcription factor initially identified for its role in segmentation of the anteroposterior body axis in Drosophila and mice (Morata and Lawrence, 1975; Millen et al., 1994). Based on studies of midbrain dopaminergic neurons in double mutants of the Engrailed homologues en-1 and en-2, these genes have also been ascribed effects on neuronal survival (Alberi et al., 2004) and cell fate decisions (Simon et al., 2005). Recent data showed that, whereas en-1 plays a sustained role in tectal development, En-2 expression is a major prerequisite for correct cerebellar

Abbreviations: ASD, Autism Spectrum Disorders; DEF, differential expression factor; En-2, Engrailed-2; ER, endoplasmic reticulum; EST, expressed sequence tags; GC, granule cell; P, postnatal day; PC, Purkinje cell.

* Corresponding author. Institute of Anatomy, Anatomy and Cell Biology, University of Bonn, Nussallee 10, D-53115 Bonn, Germany. Fax: +49 0228737301.

E-mail address: s.baader@uni-bonn.de (S.L. Baader). development (Sgaier et al., 2007). Overexpression of En-2 in late embryonic and postnatal cerebellar Purkinje cells (PCs) of L7En-2 transgenic mice revealed that En-2 is important for the proper differentiation of PCs, leading to smaller cell somata, a delayed arrangement of PCs in their characteristic monolayer, and a smaller PC dendritic tree (Jankowski et al., 2004). Whereas cell survival and cell fate determination by En typically affects early development, the morphogenetic activities of En observed in PCs are an example of its regulation of terminal differentiation and morphogenesis. Actually, PC-specific overexpression of En-2 obliterates an endogenous spatiotemporal pattern of En-2 during the early post-mitotic maturation of these cells which is critical not only to cellular morphogenesis, but also to parasagittal compartmentation and organization of afferent cortical innervations (Baader et al., 1999).

The quest for a mechanistic understanding of correct En-2 expression and function is also motivated by the findings that en-2 is a susceptibility gene for Autism Spectrum Disorders (ASD) (Benayed et al., 2005; Gharani et al., 2004). Similar to the L7En-2 phenotype, cerebella 
of ASD patients showed cell loss, abnormal neuronal differentiation, and incorrect wiring of the cerebellar cortex (Ritvo et al., 1986; Bauman and Kemper, 2005; Schaefer et al., 1996; Palmen et al., 2004; Tabuchi et al., 2007).

Current mechanistic concepts of Engrailed function include a role as a transcription factor in regulating a developmental genetic program, and as a diffusible factor in regulating axonal wiring (Brunet et al., 2005). In order to unravel biological processes which are associated with En-2 function in L7En-2 mice, we aimed to identify differential gene expression in cerebella of L7En-2 as compared to wild type mice and to cluster these genes into functional groups. Our analysis, based on in situ hybridizations and array analysis, identified a panel of genes previously linked to cell compartmentation. Electron microscopical data showed that the amount of Golgi stacks and cisternae of endoplasmic reticulum were locally reduced.

\section{Results}

\section{Array hybridization and verification}

In order to unravel cellular processes linked to the expression of Engrailed-2 (En-2), we compared gene expression in cerebella of wild type and L7En-2 transgenic mice during postnatal development. Even though En-2 expression is specifically altered only in Purkinje cells (PCs) of L7En-2 cerebella, we chose whole cerebella for our analysis. Technically, this helps to avoid artifacts that might be associated with PC isolation and sorting. Biologically, this approach holds the potential to also identify genes regulated indirectly in cells other than the primarily targeted PC neurons. Array analysis was performed using cerebellar tissue prepared from newborn (P0), seven day old (P7) and from adult (6 to 12 month old) mice. These developmental time points fall into periods when PC dendritogenesis and granule cell differentiation is about to begin (P0), when PC dendritic differentiation and synaptic integration of cerebellar neurons is prominent (P7), and finally, when the cerebellar cortex is mature (adult).

Of 24960 genes represented in the array used, 9925 were expressed in cerebellar tissue at P0. This proportion of expressed genes persisted during the first postnatal week (9467 genes) and then dropped to 7232 expressed genes which favourably compares with data reported by Kagami and Furuichi (2001). We defined a gene to be differentially expressed when it showed an at least two-fold change (up or down) in spot intensity as compared to controls, in at least 3 of the 4 replicate analyses made; moreover, the absolute difference in spot intensity had to amount to at least 20 units which was the average background intensity over all filters used (we refer to this procedure as the standard method). Using these criteria, we found a total of 133 genes regulated in L7En-2 as compared to wild type mice at P0. Of these, only 6 were up-regulated, and 127 were downregulated in L7En-2 animals. At P7, of 9467 genes, 449 genes were differentially expressed (325 down-, and 124 up-regulated). In adult wild type and L7En-2 mice, the number of differentially expressed genes dropped to 38 out of 7232 genes. The numbers of up- and downregulated genes were roughly equal (18 vs. 20, respectively) (see also Table 1). Permutation testing (Landgrebe et al., 2002; Boer et al., 2001) revealed that this preferred negative regulation is not an intrinsic property of the array technique used but a result of prolonged En-2 expression. As En-2 is known to primarily act as a repressor of transcription (Tolkunova et al., 1998), we thus conclude that the data obtained by array analysis faithfully reflect differences in gene expression between wild type and L7En-2 cerebella.

To follow up on these array data, we selected 10 genes (ap2a1, cck, crmp5, mtss1, notch-1, pvalb, rac1, rhoB, strn, tspan5) which were identified as differentially expressed, at least at some time points, in array analysis, and which were known to be expressed in the cerebellar cortex. The expression of these 10 genes was investigated by in situ hybridization, PCR or Western blotting, and the expression of five of them (cck, mtss1, pvalb, strn, tspan5) was found to differ in L7En-2 mice as compared to wild type mice.

Ten additional genes classified as not-regulated based on our array analysis (aldoc, apoa4, cds-2, crmp1, epha4, pcp-2(L7), s100b, sema3a, syp, vav2) were included in our further analysis. These genes had been previously associated with En-2 function and/or can be presumed to relate to the morphological phenotype of L7En-2 mice. Of these 10 genes, four (aldoc, epha4, pcp-2(L7), sema3a) were found to be differentially expressed by in situ hybridization or Western blotting. However, differential expression was either restricted to particular regions of the cerebellar cortex (analyzed by in situ hybridization: ephA4; see Suppl Fig. 1), or differences in expression were rather faint (30\%) (analyzed by Western blotting and immunohistochemistry: Aldoc, L7/pcp-2 ; Sanlioglu et al., 1998; by in situ hybridization: sema3a, (Suppl Fig. 2)), and thus clearly below the rather stringent cut-off of our standard selection procedure.

Intriguing genes found to be differentially expressed in L7En-2 and wild type mice, either in array analysis or in known patterns of gene expression, were cholecystokinin (cck), missing in metastasis 1 (mtss1), parvalbumin (pvalb), and tetraspanin-5 (tspan5). By array analysis, $c c k$ was found highly expressed within the cerebellar cortex throughout development. The ratio between L7En-2 and wild type samples was among the lowest found by array analysis, and the data were highly reproducible between different array experiments (see Supplementary data, Tables 1-3). In the cerebella of P0 wild type animals, $c c k$ mRNA was evidently localized within the PC layer of the anterior lobe, showing a clear-cut border of gene expression at the posterior side of the primary fissure right before the apex of the central lobe (Fig. 1). At P7, a strong cck hybridization signal could be observed in PCs with a rostrocaudal distribution as described for P0 animals. In adult wild type mice, expression extended more posteriorly, up to the anterior half of lobule IX. In contrast, in L7En-2 mice, no in situ hybridization signal could be observed at any time point. This lack of signal was not due to regional differences of $c c k$ expression along the mediolateral axis, since frontal sections revealed ubiquitous expression, or lack thereof, along this axis, in wild type and L7En-2 animals, respectively. Mesencephalic ventricular regions showed comparable hybridization signals in L7En-2 and wild type tissue documenting comparable hybridization efficiency in both tissue sections (arrows in Fig. 1).

Missing in Metastasis ( $\mathrm{mtss} 1 / \mathrm{mim} / \mathrm{beg} 4)$ is involved in cytoskeletal arrangements, specifically in actin polymerization and bundling and

Table 1

Identified genes by array analysis

\begin{tabular}{|c|c|c|c|c|c|c|c|c|c|c|}
\hline Age & Repressed sum & $\%$ & Annotated & Not annotated & Activated sum & $\%$ & Annotated & Not annotated & Expressed & $\%$ of 24,960 \\
\hline$\overline{\mathrm{PO}}$ & 127 & 1.28 & 60 & 67 & 6 & 0.06 & 4 & 2 & 9925 & 39.76 \\
\hline P7 & 325 & 3.43 & 177 & 148 & 124 & 1.31 & 71 & 53 & 9467 & 37.93 \\
\hline Ad & 18 & 0.25 & 14 & 4 & 20 & 0.28 & 9 & 11 & 7232 & 28.97 \\
\hline
\end{tabular}

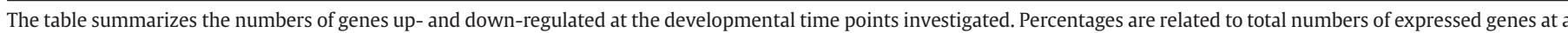

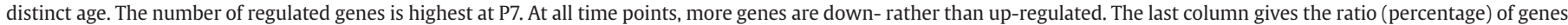
found to be expressed relative to the total number of genes $(24,960)$ represented on the array. 

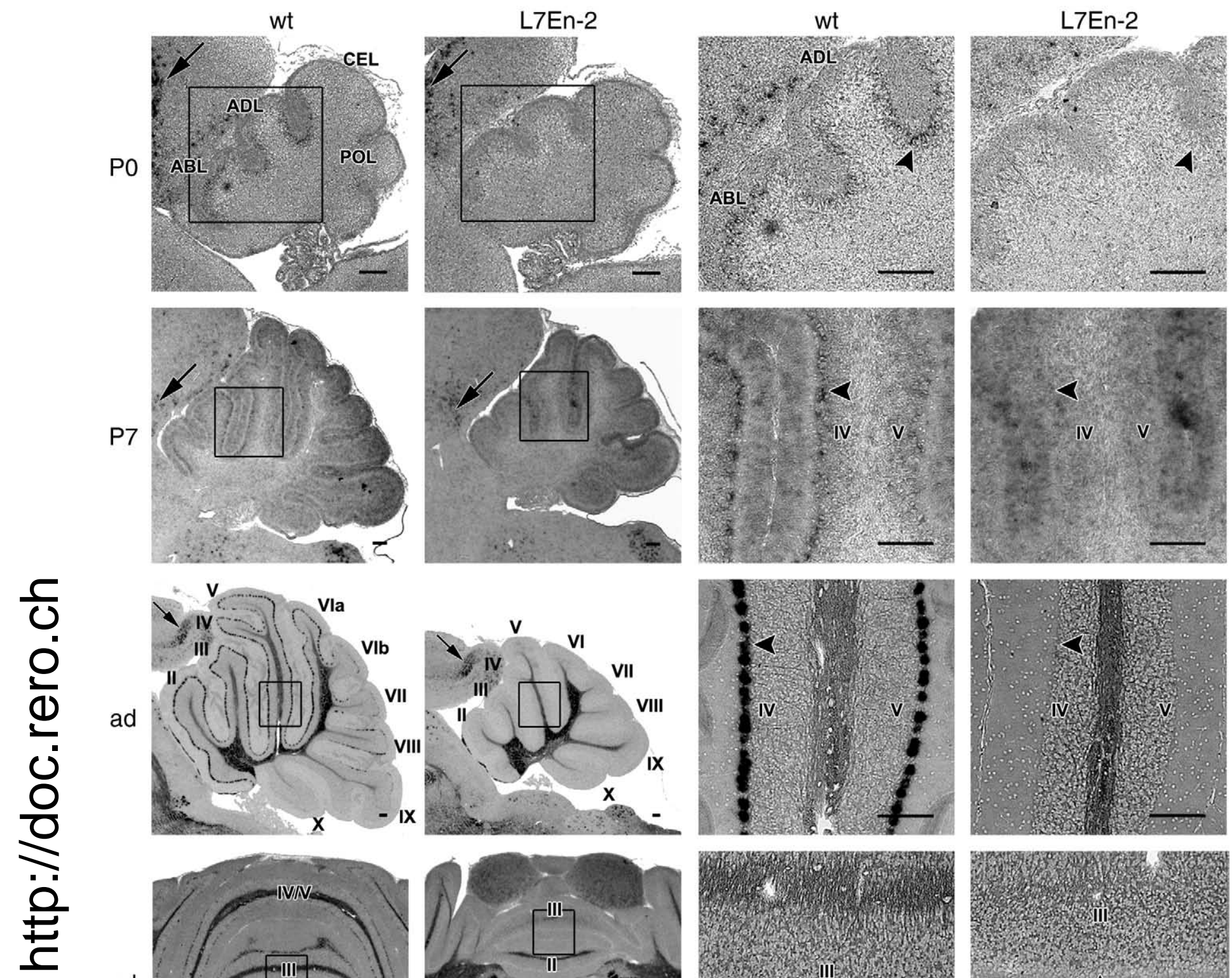

P7
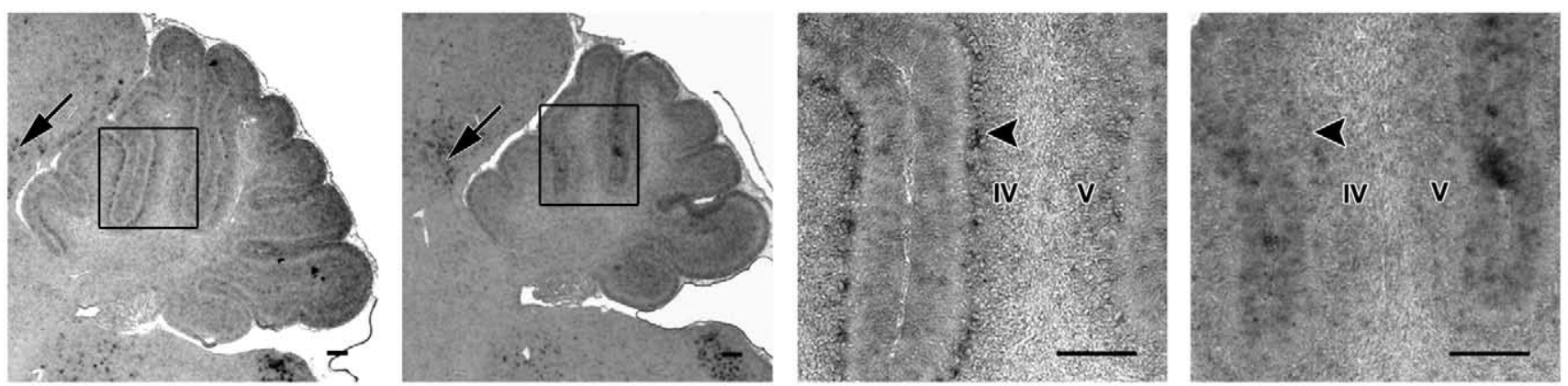

ad
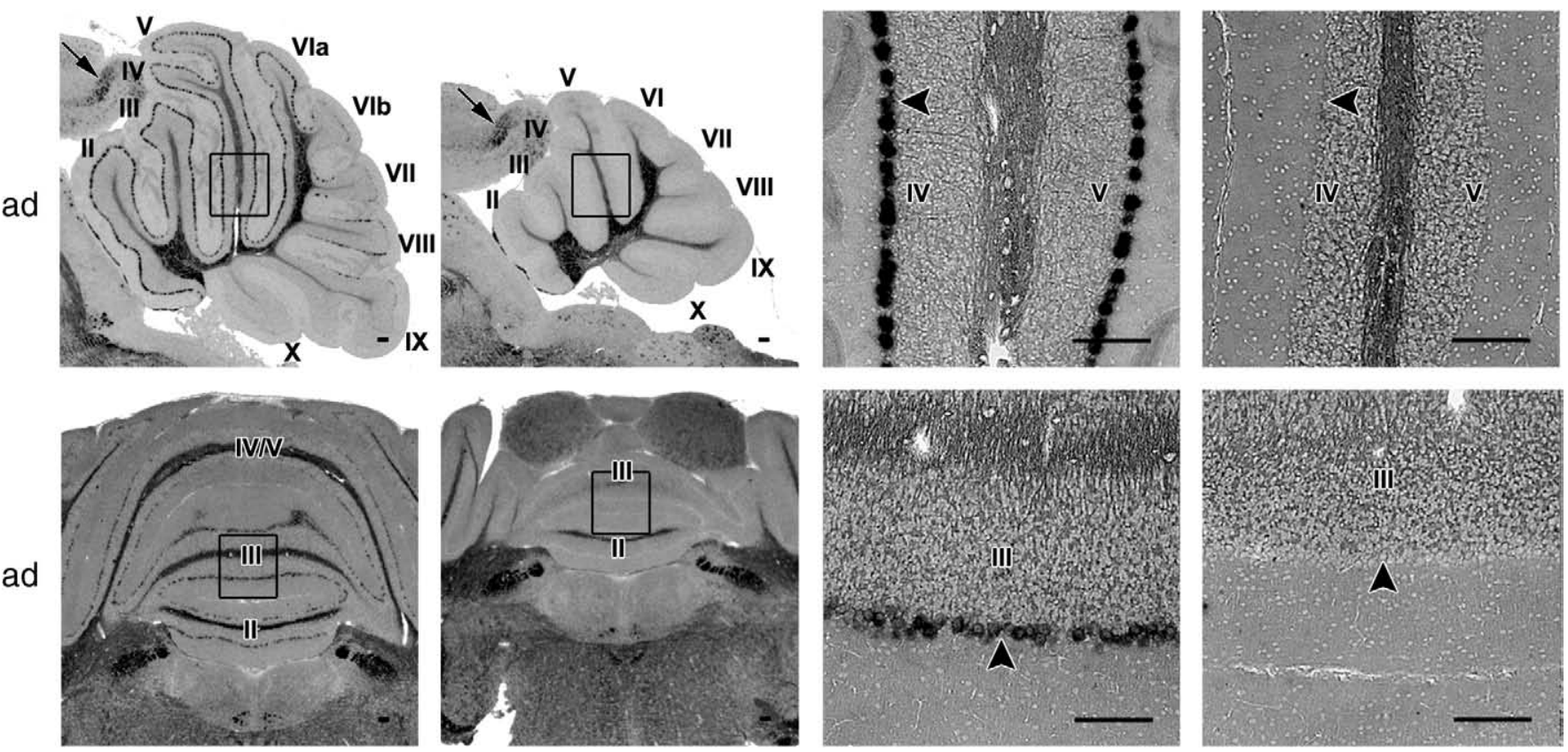

Fig. 1. Expression of cholecystokinin ( $c c k$ mRNA in L7En-2 and wild type (wt) cerebella. In situ hybridizations were performed on cerebella of newborn (P0), seven day old (P7) and adult (ad) mice. Anterior is to the left, posterior to the right in sagittal sections (upper three rows). The bottom row displays images of frontal sections. Abbreviations used are: ABL anterobasal lobe, ADL anterodorsal lobe, CEL central lobe, POL posterior lobe. Roman numbers mark vermal lobules. The PC layer is marked by arrowheads. Arrows indicate the midbrain area showing comparable staining intensity in both genotypes. Scale bars: $100 \mu \mathrm{m}$ in all images.

has been implicated in cellular migration (Bompard et al., 2005; Lin et al., 2005). Array analysis indicated that $m$ tss 1 mRNA expression was down-regulated in L7En-2 animals around P7, but not in newborns or in adults (Table 2). Consistently, mtss1 expression was found in PCs of wild type cerebella throughout postnatal development, and it was missing up to P7 in En-2 overexpressing PCs (Fig. 2). After P7, mtss1 signal in PCs of L7En-2 mice gradually increased to normal levels at P15. A strong mtss1 signal was found in the internal granule cell layer (IGL) up to P15, both in wild type and L7En-2 mice. In adult mice, mtss 1 mRNA could only be observed in wild type PCs, and to a lesser degree in L7En-2 PCs. This clearly documents a PC-specific downregulation of $m t s s 1$ expression.
As reported previously, the calcium-binding protein Parvalbumin and tetraspanin-5 mRNA are highly expressed within PCs and basket/ stellate neurons of the cerebellar cortex (Celio, 1990; Garcia-Frigola et al., 2000). Both are down-regulated specifically in L7En-2 PCs (Jankowski et al., 2004; Juenger et al., 2005) (see also Suppl Fig. 3).

In summary, from a total of 10 genes selected by array analysis and further investigated in control experiments, the expression of five genes was found to be different in L7En-2 as compared to wild type mice. Taking into account that at least one and at most three time points have been evaluated per gene, this sums up to a total of 21 comparisons among results of array analysis and control experiments. 13 comparisons gave consistent results in array analysis and control 
Table 2

Verification of array results

\begin{tabular}{llll}
\hline Gene name & P0 & P7 & Adult \\
\hline ap2a1 & $+/-/ 0.5 /-1.0$ & $+/-/ 1.0 /<0.1$ & \\
cck & $-/$ 0.5/-2.5 & $-/ 0.6 /-0.2$ & $-/<.1 /-26.6$ \\
crmp5 & $+/-/ 0.4 /-2.3$ & $+/-/ 0.7 /-0.3$ & $+/-/ 0.8 /-0.1$ \\
mtss1 & $+/-/ \mathbf{0 . 5} /-\mathbf{1 . 2}$ & $-/ 0.1 /-3.6$ & $+/-/ 0.8 /-0.1$ \\
notch-1 & & $+/-/ 0.5 /-1.0$ & \\
Pvalb (pvalb) & & $-/ 0.5 /-2.1$ & $+/-/ 0.8 /-1.0$ \\
rac1 & & $+/-/ 2.2 / 2.7$ & \\
rhoB & & $+/-/ 2.7 / 2.4$ & \\
strn & & $+/ 2.7 / 7.0$ & $+/ 1.5 / 1.5$ \\
tspan-5 & $+/-/ 0.5 /-0.8$ & $-/ 0.2 /-2.8$ & $+/-/ 0.9 /-0.1$ \\
apoa4 & & $+/-/ 1.2 /<0.1$ & \\
aldoc (Zebrin II) & & $+/-/ 0.8 /-0.2$ & $-/ 0.8 /-0.6$ \\
cds2 & & $+/-/ 0.6 /-1.0$ & $+/-/ 0.6 /-1.6$ \\
crmp1 & $+/-/ 1.0 /<0.1$ & \\
ephA4 & $+/-/ 1.0 /<0.1$ & & \\
Pcp-2 (L7) & $-/ 0.8 /-0.2$ & $-/ 0.7 /-0.7$ & $+/-/ 1.3 / 0.2$ \\
S100b & & & $+/-/ 0.9 /-<0.1$ \\
sema3a & & $-/ 1.0 /<0.1$ & $+/ 0.8 /-0.1$ \\
Synaptophysin & $+/-/ 1.1 /<0.1$ & $+/-/ 0.9 / 0.4$ & $+/ 0.7 /-0.5$ \\
vav2 & $+0.9 /-0.1$ & $+/-/ 0.9 /-0.1$ & \\
\hline
\end{tabular}

The table provides a list of genes whose expression was investigated by in situ hybridization (small letters, italic) and/or Western blot (capital letter). Results are classified as "+" if up-regulated in L7En-2 animals, "-" if down-regulated in L7En-2 animals, or "+/-" if not appreciably regulated. The first number describes the ratio of expression levels in L7En-2 and wild type cerebella. Genes were considered regulated when they differed by at least a factor of 2. Italicized data indicate that array results could be confirmed. Verified measures derived from regulated genes are marked in bold letters. The last number is the DEF value for each gene investigated which provides a measure for differential gene expression (for details, see Experimental methods). A value above 2.0 and below -2.0 was used as the cut-off for cluster analysis experiments.

experiments (italicized values in Table 2). Among such 13 hits, seven could be verified by in situ hybridization.

\section{Clustering and annotation of differentially expressed genes}

Beyond identification of individual genes differentially expressed upon En-2 expression, the exposure of functional pathways provides an additional perspective on the consequences and functional realization of En-2 action. To follow up on this, we clustered differentially expressed genes according to their functional properties and extracted clusters of genes showing disproportional changes of expression of their constituent genes. In order to avoid bias, functional cluster assignment was done based on Gene Ontology (GO) Biological Process terms (categories) (Ashburner et al., 2000). GO functional categories significantly over-represented in the differentially expressed genes were identified by the Genome Function INtegrated Discoverer (GFINDer) software (Masseroli et al., 2004; Masseroli et al., 2005). A list of these over-represented categories is given in Table 3. A detailed list of all differentially expressed genes is provided in Supplementary data Table 4

Of the 15 over-represented functional categories (clusters) identified, those comprising genes related to subcellular localization were most apparent, in terms of gene quantity and significance (Table 3). For example, the cluster "protein localization" includes genes which are engaged in vesicle trafficking between endosomes and Golgi stacks and between the Golgi apparatus and the plasma membrane ( $r a b$ genes, snap, snx genes). This cluster also includes Spectrin beta 2 (spnb2), a cytoskeletal component important for membrane transport and protein localization. A second group of differentially expressed genes is associated with lipid metabolism. Membrane lipids are prerequisites for the synthesis of new membranes and are therefore important for neurite extension and retraction. It should not go unmentioned that we also identified a variety of gene clusters seemingly not related to process outgrowth or any cellular process associated with currently known En-2 functions. However, all of these seemingly unrelated genes are expressed in wild type cerebella (data obtained from Allen Brain Atlas at http://www.brainatlas.org/aba/), suggesting some unknown role in cerebellar histogenesis.

Functional clustering of genes is predictably dependent on the set of genes classified as differentially expressed. Various normalization and analytical approaches may lead to sizable differences in genes so identified, even in controlled replicate experiments (reviewed in Quackenbush, 2001). One approach to address this issue has been to select only those genes which are consistently identified in repeated analysis (Fischer et al., 2005). Here, we defined a measure, the DEF value (differential expression factor), which incorporates inter-array variability to yield a summary measure for the stringency by which a gene is judged as differentially expressed. In contrast, the standard selection procedure focuses on genes with a predefined minimum of expression, thus eliminating genes expressed at low levels; it also implements a fixed level of inter-array concordance. Consequently, applying the DEF criteria led to the consistent identification of a larger set of genes as differentially regulated as would have been selected by the standard procedure. Thus, only some $61 \%$ of the genes identified by the DEF value at P7 were also found to be differentially expressed by the standard selection procedure. This relation amounted to $62 \%$ in newborn and $65 \%$ in adult mice.
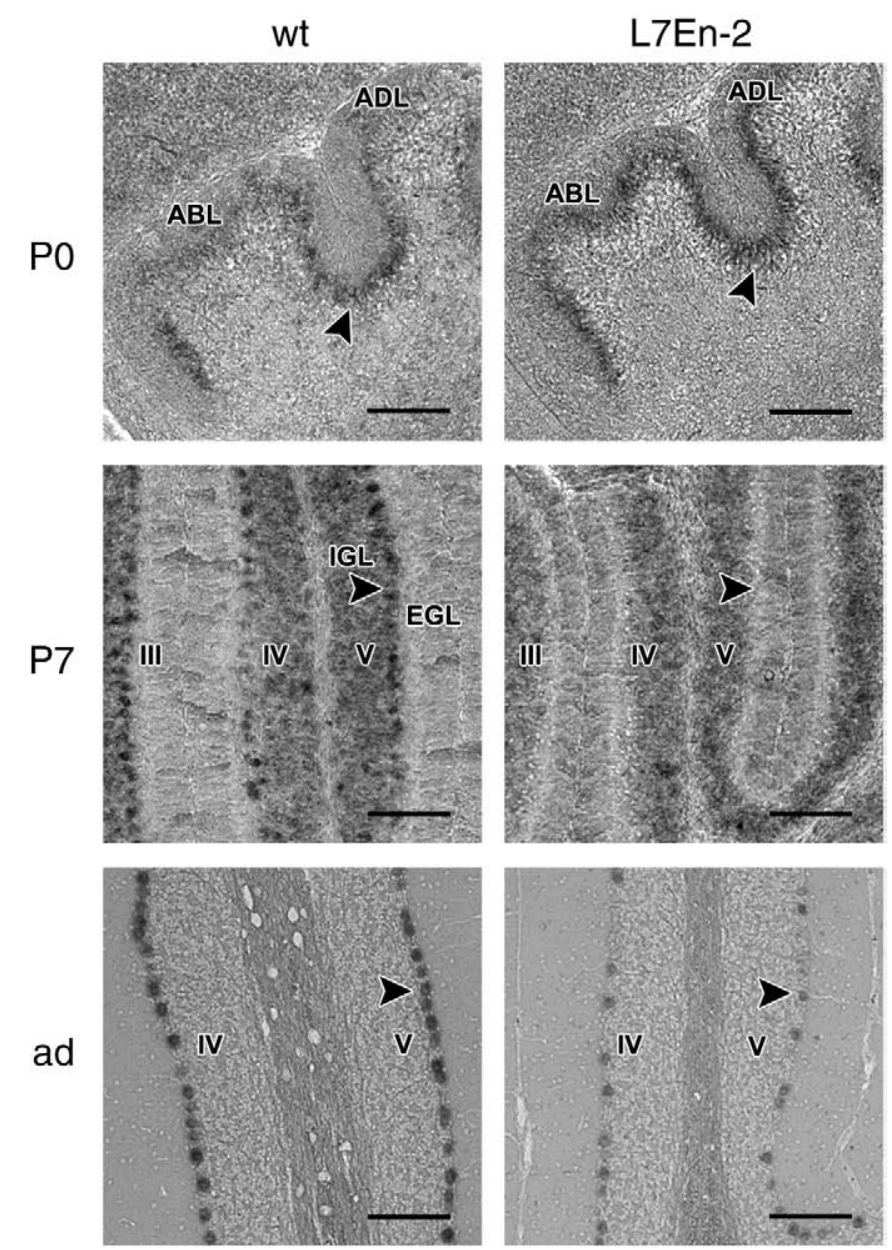

Fig. 2. Expression of missing in metastasis (mtss1) mRNA in L7En-2 and wild type (wt) cerebella. In situ hybridizations were performed on cerebella of newborn (P0), seven day old (P7) and adult (ad) mice. Pictures were taken from sagittal sections where anterior is to the left, and posterior to the right. Abbreviations used are: ABL anterobasal lobe, ADL anterodorsal lobe, EGL external granule cell layer, IGL internal granule cell layer. Roman numbers mark vermal lobules. The PC layer is marked by arrowheads. Scale bars: $100 \mu \mathrm{m}$ in all images. 
Table 3

Annotation and clustering of differentially expressed genes according to their over-represented Gene Ontology Biological Process categories

\begin{tabular}{|c|c|c|c|c|c|c|c|c|c|}
\hline \multirow[t]{2}{*}{ Name } & \multirow[t]{2}{*}{ Function } & \multirow{2}{*}{$\frac{\mathrm{P} 0}{\text { Ratio/DEF }}$} & \multirow{2}{*}{$\frac{\mathrm{P7}}{\text { Ratio/DEF }}$} & \multirow{2}{*}{$\frac{\mathrm{Ad}}{\text { Ratio/DEF }}$} & \multirow[t]{2}{*}{ Name } & \multirow[t]{2}{*}{ Function } & \multirow{2}{*}{$\frac{\mathrm{P} 0}{\text { Ratio/DEF }}$} & \multirow{2}{*}{$\frac{\mathrm{P} 7}{\text { Ratio/DEF }}$} & \multirow{2}{*}{$\frac{\text { Ad }}{\text { Ratio/DEF }}$} \\
\hline & & & & & & & & & \\
\hline Akap10 & Protein localization & & $<0.1 /-3.5$ & & Lpgat1 & Lipid metabolism & & $0.5 /-2.1$ & \\
\hline Arhgap17 & Protein localization & $0.5 /-1.0$ & & $0.3 /-10.1$ & Pla2g4a & Lipid metabolism & & $<0.1 /-6-9$ & \\
\hline $\operatorname{Cog} 3$ & Protein localization & & $3.2 / 2.4$ & & Pnlip & Lipid metabolism & & $0.1 /-3.8$ & \\
\hline Ii & Protein localization & & $3.8 / 2.8$ & & Slc5a1 & Lipid metabolism & & $0.4 /-4.5$ & \\
\hline Napa & Protein localization & & $0.5 /-0.7$ & & Arhgap17 & Organization/biogenesis & $0.5 /-2.0$ & & $0.3 /-10.1$ \\
\hline Oxa11 & Protein localization & & $0.3 /-2.6$ & & Epb4.112 & Organization/biogenesis & & $0.6 /-0.4$ & \\
\hline Rab22a & Protein localization & & $0.2 /-5.0$ & & Epb4.113 & Organization/biogenesis & & $0.5 /-1.0$ & \\
\hline Rab32 & Protein localization & & $2.6 / 2.6$ & & Peci & Organization/biogenesis & & $2.2 / 1.2$ & \\
\hline Rab35 & Protein localization & & $2.0 / 6.0$ & & Pex11a & Organization/biogenesis & & $0.1 /-3.8$ & \\
\hline Rhob & Protein localization & & $2.7 / 2.4$ & & Prkci & Organization/biogenesis & & & $0.5 /-2.4$ \\
\hline Scfd1 & Protein localization & & $0.4 /-3.6$ & & Pxmp3 & Organization/biogenesis & & $0.5 /-1.9$ & \\
\hline Sfrs1 & Protein localization & & $0.5 /-5.0$ & & Ddx5 & Regulation of metabolism & & $0.3 /-7.7$ & \\
\hline Snap23 & Protein localization & & $2.5 / 4.9$ & & Ebf1 & Regulation of metabolism & & $0.3 /-1.8$ & \\
\hline Snx10 & Protein localization & & $0.1 /-2.4$ & & Kitl & Regulation of metabolism & & $0.4 /-1.6$ & \\
\hline Snx15 & Protein localization & & $0.2 /-2.0$ & & Pparbp & Regulation of metabolism & & $0.1 /-4.0$ & \\
\hline Spnb2 & Protein localization & & $0.4 /-2.4$ & & Rac1 & Regulation of metabolism & & $2.2 / 2.7$ & \\
\hline Synj2bp & Protein localization & & $0.2 /-3.2$ & & Skiip & Regulation of metabolism & & $0.4 /-1.8$ & \\
\hline Tmed7 & Protein localization & & $0.2 /-3.0$ & & Smad5 & Regulation of metabolism & & $0.4 /-2.0$ & \\
\hline Tram1 & Protein localization & & $0.3 /-3.2$ & & $\mathrm{Ccl} 22$ & Response to external stimulus & $0.5 /-1.1$ & & \\
\hline Vdp & Protein localization & & $2.4 / 0.9$ & & Chi3l3 & Response to external stimulus & $0.5 /-1.4$ & & \\
\hline Vps26 & Protein localization & & $0.1 /-4.7$ & & Mtap1a & Response to external stimulus & & $2.7 / 2.7$ & \\
\hline 1810062014Rik & Localization & $0.5 /-1.5$ & & & Nfkbiz & Response to external stimulus & $0.5 /-4.8$ & & \\
\hline Ap2a1 & Localization & $0.5 / 1.0$ & & & Opn3 & Response to external stimulus & & $0.2 /-2.1$ & \\
\hline Ap2b1 & Localization & $3.7 / 2.5$ & & $4.0 / 3.7$ & Pde6d & Response to external stimulus & & $2.9 / 2.3$ & \\
\hline Arhgap17 & Localization & $0.5 /-1.0$ & & & Tlr7 & Response to external stimulus & $0.5 /-1.3$ & & \\
\hline Gga2 & Localization & $4.4 / 2.1$ & & & Actn2 & Muscle contraction & & $3.1 / 5.3$ & \\
\hline Ghr & Localization & $0.5 /-1.2$ & & & Ryr1 & Muscle contraction & & $0.1 /-7.1$ & \\
\hline Ndel1 & Localization & $0.5 /-1.1$ & & & Tnni1 & Muscle contraction & & $<0.1 /-11.3$ & \\
\hline Parp9 & Localization & $0.5 /-1.1$ & & & Tnnt2 & Muscle contraction & & $0.2 /-3.6$ & \\
\hline Rab21 & Localization & $0.4 /-1.4$ & & & Wdr21 & Muscle contraction & & $0.1 /-12.4$ & \\
\hline Slc25a17 & Localization & $0.5 /-1.5$ & & & Ing1 & Cell cycle & & $3.3 / 3.5$ & \\
\hline Slc30a6 & Localization & & $0.4 /-2.4$ & & Nf2 & Cell cycle & & $2.4 / 1.8$ & \\
\hline Snap23 & Localization & & $2.5 / 4.9$ & & Rhob & Cell cycle & & $2.7 / 2.4$ & \\
\hline $\operatorname{Timm} 23$ & Localization & $0.5 /-2.0$ & & $0.3 /-10.1$ & Tusc4 & Cell cycle & & $0.5 /-0.9$ & \\
\hline Tmed5 & Localization & $0.6 /-1.1$ & & & Cck & Development & & & $<0.1 /-26.6$ \\
\hline 0610009K11Rik & Protein metabolism & $0.3 /-2.1$ & & & Meox2 & Development & $0.5 /-0,9$ & & \\
\hline 3732413I11Rik & Protein metabolism & $0.5 /-3.7$ & & & Msh6 & Development & $0.5 /-1.5$ & & \\
\hline Ankib1 & Protein metabolism & $0.5 /-1.9$ & & & Six 3 & Development & $0.5 /-1.0$ & & \\
\hline Ap2b1 & Protein metabolism & $3.7 / 2.5$ & & $4.0 / 3.7$ & AW742319 & Signal transduction & $0.5 /-3.1$ & & \\
\hline Fzr1 & Protein metabolism & $0.5 /-2.0$ & & & Azi2 & Signal transduction & $0.3 /-3.4$ & & \\
\hline Gga2 & Protein metabolism & $4.4 / 2.1$ & & & Smad5 & Signal transduction & & $0.4 /-2.0$ & \\
\hline Nmt1 & Protein metabolism & $0.4 /-1.8$ & & & Spnb2 & Signal transduction & & $0.4 /-2.4$ & \\
\hline Pml & Protein metabolism & $0.5 /-1.4$ & & & Pparbp & Hormone metabolism & & $0.1 /-4.0$ & \\
\hline Sfrs1 & Protein metabolism & & & $0.5 /-2.0$ & Ttr & Hormone metabolism & & & $0.4 /-7.3$ \\
\hline Wwp1 & Protein metabolism & $0.5 /-1.4$ & & & Msh6 & DNA metabolism & $0.5 /-1.5$ & & \\
\hline Apoa4 & Lipid metabolism & & $0.2 /-7.3$ & & Sfrs1 & RNA metabolism & & & $0.5 /-2.0$ \\
\hline Cds2 & Lipid metabolism & & $0.6 /-1.0$ & & $\mathrm{Clec} 2 \mathrm{~g}$ & Regulation of cell differentiation & $0.5 /-1.8$ & & \\
\hline Lass4 & Lipid metabolism & & $<0.1 /-13.7$ & & & & & & \\
\hline
\end{tabular}

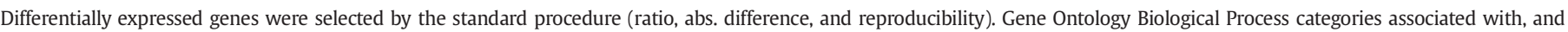

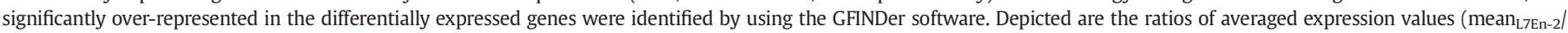

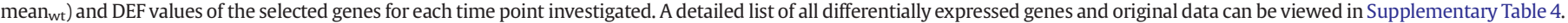

As expected, the biological processes identified as first and foremost affected by En-2 overexpression differed somewhat, depending on whether functional cluster analysis was applied to genes selected by the standard procedure or by the DEF selection criteria. In the latter, changes were more significant in GO categories related to homeostasis and metabolic processes. However, terms describing cellular differentiation, maturation and subcellular protein localization were identified with both approaches, thus supporting the view that En-2 overexpression in cerebellar PCs substantially affects genes involved in cellular transport and protein localization.

\section{Altered ultrastructure of Purkinje cells expressing Engrailed-2 postnatally}

Since transport and localization of membranes and membrane proteins are dependent on the Golgi apparatus and endoplasmic reticulum, we compared the distribution and morphology of these organelles in PCs derived from wild type and transgenic L7En-2 mice. We first chose nine day old animals because it could be shown that PCs show a particular compartmentalized ultrastructure at this developmental time point. In wild type PCs, Golgi stacks could be found within somatic and dendritic compartments. Characteristically, additional Golgi cisternae were located at the axonal part of the cell soma close to the nucleus (Fig. 3). These stacks could be observed in 75 out of 83 wild type PCs which were cut in a plane where the nucleus spanned at least $50 \%$ of the cell soma diameter (for more details see Experimental methods). Whereas the dendritically localized Golgi apparatus was also seen in L7En-2 PCs, Golgi stacks at the axonal pole of the somata of these mutant cells were far less frequent (20 out of 75 PCs, Fig. 3E). In addition, the length distribution of granular endoplasmic reticulum segments was significantly shifted towards shorter ER segments in L7En-2 as compared to wild type PCs (Fig. 3F, Wilcoxon signed rank test, $p=0.0104$ ). These L7En-2 PCs with altered ultrastructural morphologies did not show any characteristics of apoptotic cells. PCs of 

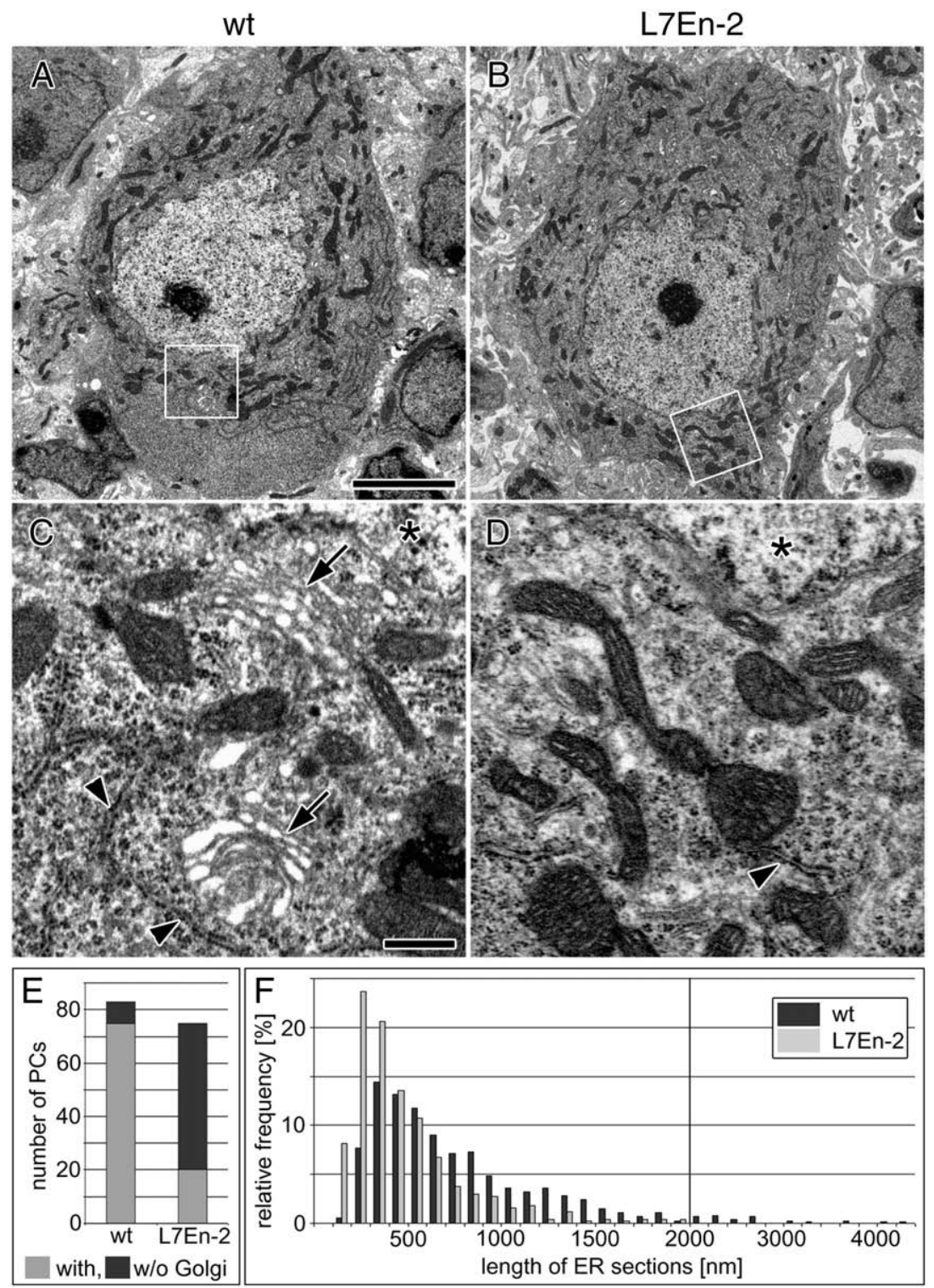

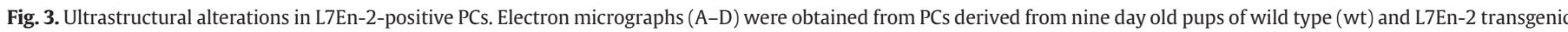

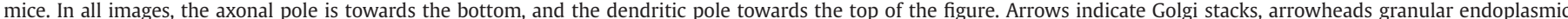

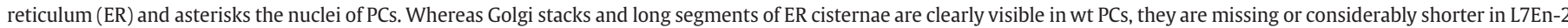

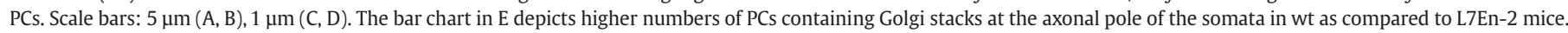
The frequency plot (F) shows significantly shorter segment lengths of ER cisternae in L7En-2 PCs as compared to wt PCs.

adult wild type and L7En-2 mice did not show differences in the parameters described above, thus paralleling the time frame of differential gene expression analysis.

\section{Discussion}

Here, we report changes of gene expression in the developing cerebellum subsequent to the continued and forced expression of Engrailed-2 (En-2) in Purkinje neurons beyond the stage of its physiological transient expression in these cells. Our results show that the delayed morphogenesis of En-2 overexpressing Purkinje cells (PCs) goes along with conspicuous changes in the expression of genes functional in cellular transport, membrane biogenesis and vesicular trafficking. These changes in gene expression are paralleled by greatly diminished Golgi stacks and morphologically altered endoplasmic reticular cisternae at the axonal pole of L7En-2 PC somata. This sheds light on the mechanistic basis how proper regulation of En-2 is involved in fine-tuning terminal differentiation and morphogenesis.
Intracellular transport and sorting of vesicles are targeted by Engrailed-2 in cerebellar Purkinje cells

The present array analysis revealed high numbers of differentially expressed genes, which are associated with intracellular transport and sorting. Long distance transport and peripheral targeting of vesicles is critically dependent on the cytoskeletal organization. Spectrin beta2, identified here as down-regulated in En-2 overexpressing Purkinje cells, forms protein scaffolds beneath the plasma membrane and restricts transport to specialized membrane domains (Dubreuil, 2006). Similarly, Mtss1 regulates Cortactin and N-WASP-mediated actin polymerization (Lin et al., 2005) and is localized to dendritic spines (Mattila et al., 2007). In addition, Actinin 2 up-regulated in L7En-2 cerebella interacts with actin filaments and postsynaptic density proteins, and recruits glutamate receptors to dendritic spines (Wyszynski et al., 1998). Intriguingly, the observation that several cytoskeletal genes were regulated in L7En-2 mice is reminiscent of findings that functionally similar genes are also affected by ablation of 
En homologues in mice and Drosophila. These include cytoskeletonassociated genes such as polyhomeotic (Serrano et al., 1995), $\beta 3-$ tubulin (Serrano et al., 1997), map1b (Montesinos et al., 2001), connectin/neuroglian (Siegler and Jia, 1999), and bpag1 (Mainguy et al., 1999). Yet while the actual set of regulated genes is different - most probable due to the different spatio-temporal alterations of En-2 expression induced in both genotypes -, both gene sets can be functionally linked to cellular morphogenesis.

Even before transport and targeting, vesicle formation and maturation is critical for cellular morphogenesis. In this context, it is noteworthy that several genes impinging on these processes are regulated in L7En-2 mice, including tmed5 and vps26, as well as tram1. This suggests that the formation of secreted proteins and the endoplasmic reticulum-to-Golgi transport is reduced in these mice. Conversely, $\operatorname{cog} 3$ was found to be upregulated in L7En-2 mice. As Cog complex proteins are needed for the integrity and dynamics of the Golgi complex (e.g., (Shestakova et al., 2007) and references therein), this is another indication that En-2 overexpression interferes with intracellular transport. Intriguingly, this goes along with a conspicuous absence of Golgi apparatus from the axonal pole of L7En-2 PCs. We currently do not know whether this reflects local instability or intracellular redistribution of this structure.

The overall changes in gene expression following En-2 overexpression just discussed are consistent with the view that the generation of vesicles from the Golgi might be increased. In contrast, expression of genes related to endocytosis such as spectrin beta2, synaptojanin binding protein and ap2 adaptor protein (Zhang et al., 1994; Hayes et al., 2000; Mani et al., 2007) were all found down-regulated. Similarly, the transport back to the trans-Golgi-network might be hindered in L7En-2 PCs since expression of genes involved in these processes, gga2 and rab21 (Black and Pelham, 2000; Simpson et al., 2004) were found to be reduced following En-2 overexpression. Finally, genes involved in recycling of endocytic vesicles (rab22a, snx10 and snx15; Magadan et al., 2006; Qin et al., 2006; Phillips et al., 2001) were also reduced in expression. Taken together, the set of differentially expressed genes following En-2 overexpression pinpoint to a dysregulation of vesicle formation, maturation and sorting; such interpretation is fully consistent with the morphologically observed changes in L7En-2 PCs, from the conspicuous absence of the Golgi apparatus from the axonal pole, to the delayed and reduced dendritogenesis in these cells (Jankowski et al., 2004).

Intriguingly, it has been shown that limiting membrane transport has not only a general and indiscriminate effect on process formation, but that limiting the ER-to-Golgi transport may specifically affect membrane supply to dendrites, whereas axon growth was not affected (Ye et al., 2007). Such a differential effect on axon and dendrite development is also obvious in L7En-2 mice, which display a delayed dendritic development, but in which axon growth and regeneration are unaffected (Jankowski et al., 2004 and unpublished observations). Further support for a dendrite specific effect of En-2 overexpression comes from our observation that Rho-family GTPases rhoB, rab22a, rab32, and rab35 were identified as differentially expressed in L7En-2 mice. The functionally related dar genes in Drosophila, and the homologues rab1, sar1, and sec23 were identified as important regulators of dendritic development (Ye et al., 2007). In addition, clathrin mediated endocytosis which seems to be affected in L7En-2 cerebella is required for basolateral protein transport, but does not affect polarity of apical proteins (Deborde et al., 2008). The down-regulation of secretionassociated genes arhgap17 and napa that function in vesicle fusion with the plasma membrane (Harada et al., 2000; Chae et al., 2004) should also affect dendritogenesis, which is secretion-dependent (Ye et al., 2007). Thus, the cellular and systemic phenotypes observed following manipulation of En-2 expression can now be related to a set of effector genes involved in directed transport and localization.

Besides cytoskeletal genes and genes related to protein localization and cellular transport, we also found genes related to lipid metabolism distinctly regulated following En-2 overexpression. The synthesis of membrane constituents such as sphingolipids or lysophosphatidic acid and their transport are essential for survival of cells and their dysfunction can cause apoptotic cell death (Futerman et al., 1998; Cooper et al., 2006). Consistently, PC degeneration mutants show abnormal inclusions and organelles within PC somata (Landis and Mullen, 1978) and express endoplasmic reticulum-stress-related factors (Kyuhou et al., 2006; Zhao et al., 2005). This may help to rationalize the morphological phenotype observed in cerebella of mice overexpressing En-2 in PCs, which is characterized not only by a delayed and runted morphogenesis (Jankowski et al., 2004), but also by PC death (Baader et al., 1998) and changes in cellular compartmentation and localization of membranous structures.

If we consider En-2 as a regulator of transport and localization in cerebellar PCs, what then is its physiological function during PC development? Based on our data, we propose that En-2 is involved in down-regulating organelle transport directed towards the dendritic pole of the soma which, in normal PCs, is expected to happen prenatally. Subsequent to the physiological shut-down of En-2 expression in PCs shortly after birth, dendrites start to develop. Thus, En2 might function as a repressor for dendritogenesis, which is active during the axonal growth phase. Consistent with this view, overexpression of En-2 led to a reduction in dendritically oriented transport and thus reduced dendritogenesis. The selective lack of Golgi stacks at the axonal pole of L7En-2 PCs is also in keeping with this view, given that this organelle is known to be localized opposite to the place of the current process outgrowth (Dvorak and Bucek, 1970). In contrast to many other developmental control genes that activate transcription factor cascades, we only rarely could detect transcription factors in the list of genes associated with significantly over-represented functional categories in L7En-2 cerebella. This is consistent with the concept of En-2 not directly acting on the transcription machinery, but lying at the cusp between development and cell physiology.

\section{Cholecystokinin as a link between Engrailed-2 signaling and oxytocin} metabolism

En-2 has previously been identified as a potential susceptibility gene for ASD (Benayed et al., 2005). In this respect, our finding that cck is downregulated in L7En-2 mice is of major interest. Cck is expressed in various regions of the central nervous system, has neuromodulatory effects and impacts on dopamine-mediated behavior (Crawley et al., 1985). In the hypothalamic-pituitary system, Cck can induce oxytocin release (Bondy et al., 1989; Hashimoto et al., 2005), and oxytocin metabolism is strongly associated with ASD (Green et al., 2001; Modahl et al., 1998). Consistently, mice lacking the oxytocin gene have profound deficits in social processing and social recognition, as do rats lacking vasopressin or mice lacking the vasopressin V1a receptor ( $v 1 a R)$ (Lim et al., 2005; Winslow and Insel, 2002; Ferguson et al., 2000). The effect of En-2 on cck expression provides a first inroad to explain how En-2 might impinge on behavior. Based on expression profiles of normal brain, the amygdala is an interesting region where this pathway can be operative. The amygdala co-expresses Engrailed, the oxytocin receptor, and Cck (Kuemerle et al., 2006; Huber et al., 2005; Mascagni and McDonald, 2003), and it is considered to be strongly involved in ASD (Schulkin, 2007).

\section{Experimental methods}

\section{Animal care}

L7En-2 mice (Baader et al., 1998) used for this study were handled in strict adherence to local governmental and institutional animal care regulations. Animals were generated and kept in a FVB/N background (Taconic).

Array analysis

We used Trizol (Invitrogen) to obtain $380 \mu \mathrm{g}$ of total RNA from 43 cerebella of newborn wild type (wt) animals and $370 \mu \mathrm{g}$ from 46 cerebella of newborn PCR-genotyped L7En-2 
mice. The following amounts of total RNA were obtained from older animals: $1217 \mu \mathrm{g}$ from 10 P7 wt cerebella; $1455 \mu \mathrm{g}$ from 14 P7 L7En- 2 cerebella; $710 \mu \mathrm{g}$ from 6 adult wt cerebella; $394 \mu \mathrm{g}$ from 6 adult L7En-2 cerebella. Before preparing poly(A)+-mRNA from the total RNA using Dynabeads (Invitrogen), the quality of the total RNA was checked using an Agilent bioanalyzer (Agilent Technologies). Four hundred nanograms of the mRNA was then used for reverse transcription and the following hybridization procedure. To produce labeled cDNA 400 ng of poly(A)+ RNA was mixed with $0.5 \mu \mathrm{g}$ dTV primer (anchored dT18) in a volume of $10.5 \mu \mathrm{l}$, heated $10 \mathrm{~min}\left(70{ }^{\circ} \mathrm{C}\right)$ and cooled on ice. For the following reverse transcription $\left(2 \mathrm{~h}\right.$ at $37^{\circ} \mathrm{C}$ ) $20 \mathrm{U}$ RNasin (Promega), $5.0 \mu \mathrm{l} 5 \times$ first strand buffer, $2.5 \mu \mathrm{l} 0.1 \mathrm{M}$ DTT, $0.5 \mu \mathrm{l} 20 \mathrm{mM}$ dGTP, dATP, dTTP, $5.0 \mu \mathrm{l}$ [alpha ${ }^{3}{ }^{3} \mathrm{P}$ ] dCTP $(10 \mu \mathrm{Ci} / \mathrm{ul})$, and $1 \mu \mathrm{l}$ Superscript II RT (Invitrogen) were added. Hydrolysis of RNA was performed with $1 \mu l 0.5 \mathrm{M}$ EDTA at pH $8.0,1 \mu \mathrm{l} 10 \% \mathrm{SDS}, 3 \mu \mathrm{l} 3 \mathrm{~N} \mathrm{NaOH}$ at $68^{\circ} \mathrm{C}$ for $30 \mathrm{~min}$. Afterwards, the probe was neutralized with $1 \mu \mathrm{l} 1 \mathrm{M}$ Tris $\mathrm{HCl}$ at $\mathrm{pH} 8.0$ and $3 \mu \mathrm{l} 2 \mathrm{~N} \mathrm{HCl}$ at room temperature. The probe was cleaned using a S-300 column (GE Healthcare), heated to $100{ }^{\circ} \mathrm{C}$ for $5 \mathrm{~min}$ and placed on ice until hybridization.

Whole-genome analyses were performed on the Mouse Unigene Set RZPD 1 cDNA macro-array. It contained 24,960 PCR fragments made from cDNA clones, spotted in duplicates on a $22 \times 22 \mathrm{~cm}$ nylon membrane. For hybridization, filter membranes were prehybridized in $1 \times$ Denhardt's hybridization mix $(6 \times$ SSC, $5 \times$ Denhardt's solution, $0.25 \%$ SDS, $0.5 \mu \mathrm{g} / \mathrm{ml}$ Cot-1 DNA (Invitrogen), $0.5 \mu \mathrm{g} / \mathrm{ml}$ (dA) 40 oligonucleotide) at $65{ }^{\circ} \mathrm{C}$ for $2 \mathrm{~h}$. The labeled cDNA sample was added to the prehybridization solution and the filter membranes hybridized at $65{ }^{\circ} \mathrm{C}$ for 20 to $24 \mathrm{~h}$. Washing was done at $65{ }^{\circ} \mathrm{C}$ with $1 \times$ SSC, $0.1 \%$ SDS at $65{ }^{\circ} \mathrm{C}(20 \mathrm{~min})$, twice in $0.3 \times$ SSC and $0.1 \%$ SDS for $10 \mathrm{~min}$ and finally in $0.1 \times$ SSC and $0.1 \%$ SDS for $10 \mathrm{~min}$. After covering with saran wrap, filter membranes were exposed to a PhosphorImager screen for 20 to $24 \mathrm{~h}$. The screen was analyzed using a Fuji FLA3000 PhosphorImager. Data analysis was performed with the commercial software package AIDA Metrix V3.21 2002 (Raytest) and Microsoft Access.

The following procedures were used to analyze filter membrane images. First, a user-defined template was created which contains a grid of circles surrounding each dot on the filter membrane. Each circle was assigned with an identifier attributed to a distinct cDNA clone. Thereby, the localization of identical cDNA clones could be identified. Finally, the obtained grid was laid over the filter membrane images and fine tuning of grid adjustment was done manually. In a next step, the gray values for each circle were measured by the AIDA Metrix program, and the spot intensity was calculated by integrating the photo stimulated luminescence obtained. From the resulting spot intensities, background had to be subtracted. Since background intensities were not homogeneously distributed over the filter membrane, "empty" spots (array positions containing Arabidopsis MTP cDNA) located in each set of 25 spots were used to obtain a local value for background intensity (Beissbarth et al., 2000). The background subtraction was performed using the weighted background dot subtraction method of the AIDA program. Thereby, the influence of each background dot on any dot is weighted by the distance between those dots. Values of the background dots were thus set to zero. In order to exclude differences in dot intensities based on experimental conditions such as different labeling rates, hybridization efficiencies or filter membrane variations, data were normalized using the global reference dot option. This mathematical procedure refers the intensities of all background corrected spots to the mean value of all spots. After normalization, all intensity values less than 1 were set to 1 in order to avoid divisions by zero during the following mathematical procedures (Mutch et al., 2002). The complete list of genes after background subtraction and normalization is presented as supplement material (Supplementary Tables 1-3).

In order to compare Array results to other sets of experiments already published, we followed the MIAME standards (Brazma et al., 2001) and the standards described by Yang and Speed (2002).

In this work, we used two ways of selecting differentially expressed genes: one is based on the repetitive occurrence of ratio values considered to be suitable, the other method is a mathematical approach combining all array information obtained for one clone. The first method, here called standard procedure, selects clones as differentially expressed in wild type (master) and L7En-2 (client) mice (i) if the ratio (client/master) was at least 2 or at most 0.5 , (ii) if the same trend of the ratio could be observed in at least 3 out of 4 compared data points, and (iii) if the absolute difference in expression was at least 20 (Sato et al., 2005). The selection method was programmed in standard query language $(\mathrm{SQL})$ and the queries were implemented into Microsoft Access.

Although this approach is easy to use and often applied, it neglects variance and absolute expression levels. To obtain a numerical estimate of gene expression which incorporates these aspects, we used a formula similar to Tusher et al., 2001.

$$
\operatorname{DEF}(i)=\quad \log _{2}(\overline{C(i)} / \overline{M(i)}) \frac{|\overline{C(i)}-\overline{M(i)}|}{\sqrt{\left(S_{C(i)}\right)^{2}+\left(S_{M(i)}\right)^{2}}}
$$

The absolute difference is given as $\mathrm{C}-\mathrm{M}$ ( $\mathrm{C}$ client, $\mathrm{M}$ master), the ratio by $\mathrm{C} / \mathrm{M}$ for each clone $i$. $S$ is the standard deviation. Since low expression values $(<20)$ were ignored in this study, we did neglect the fact that low expression values goes parallel with low standard deviation and would therefore result in high DEF values. In order to emphasize the ratio aspect, we adapted the procedure of Yang and Speed (2002) which used the $\log _{2}$ (ratio).

In order to functionally annotate genes and reveal functional gene clusters, the GFINDer software (http://www.bioinformatics.polimi.it/GFINDer/) was used (Masseroli et al., 2004; Masseroli et al., 2005). This software allows the upload of genes from array analysis and the identification of significantly over-represented controlled annotation terms in the uploaded gene datasets. Functional cluster analysis was performed considering the Biological Process annotation categories of the Gene Ontology Consortium (Ashburner et al., 2000) as of June, 2007.

\section{In situ hybridization}

In situ hybridization was performed on paraffin embedded sections using DIC labeled RNA probes according to a protocol described previously (Juenger et al., 2005). DIG-tagged riboprobes specific for parvalbumin were prepared from plasmids. For parvalbumin, 240 bp of the rat parvalbumin cDNA (nucleotide 73-319 bp of accession number NM_022499) was inserted into pGEM3/f+. Antisense RNA was produced by linearizing the plasmid with HindIII and synthesizing the RNA using T7 RNA polymerase; sense probe was synthesized from an EcoRI-linearized plasmid using SP6 RNA polymerase. Probes for $c c k$ and $m t s s 1$ were prepared from a PCR amplified DNA flanked by T7 and T3 sequences on either side. Primers used can be obtained from the authors. In vitro transcription was performed according to Roche. RNA riboprobes were hybridized to deparaffinized sections and bound RNA probes visualized by alkaline phosphatase mediated NBT/BCIP conversion. Photographs were taken on an Axioskop 2 MOT Zeiss Microscope (Zeiss, Jena, Germany).

\section{Transmission electron microscopy}

Nine day old mice were transcardially perfused with Ringer's solution and a fixative containing 3\% glutaraldehyde and 3\% paraformaldehyde in PBS. Dissected cerebella were immersion fixed in the same fixative for $3 \mathrm{~h}$ and trimmed to sections of 600 $1000 \mu \mathrm{m}$ thickness using a Leica VT1000S vibratome (Leica, Wetzlar, Germany). These sections were postfixed in $1 \%$ PBS-buffered osmium tetroxide for $1 \mathrm{~h}$. After dehydration in graded ethanol solutions and propylene oxide, the specimens were embedded in araldite. Series of semithin sections $(1 \mu \mathrm{m})$ were cut from the midline towards roughly $100 \mu \mathrm{m}$ laterally. The sections were stained with toluidine blue/pyronine. Selected semithin sections at least $10 \mu \mathrm{m}$ apart were re-embedded for subsequent thin sectioning (Miething, 2005). All thin sections (60-70 nm) evaluated were derived from different regions, but all within the anterior lobe next to fissures II to V. This way, we made sure that each section covered a different set of PCs, and that selected regions were comparable between wild type and L7En-2 cerebella. Thin sections were stained with uranyl acetate and lead citrate. For quantitative analysis, thin sections were screened for the appearance of Golgi stacks in PCs cut at a level such that the nucleus spanned more than $50 \%$ of the cell soma diameter. A Golgi stack was defined by at least two Golgi like cisternae in close proximity to each other. In total, we analyzed 83 wild type PCs and 75 L7En-2 PCs. The length of the granular endoplasmic reticulum (ER) was measured using the PlugIn "Neuron]" of ImageJ. Granular ER was considered a clearly visible membrane cisterna which was covered at least in part by ribosomes. By using these criteria only fragments longer than $100 \mathrm{~nm}$ could be clearly identified as granular ER. This might be a reason why the frequency plot showed no or low numbers of ER segments up to $200 \mathrm{~nm}$ in length. A total of 743 ER cisternae in wild type PCs and 504 ER cisternae in L7En-2 PCs were analyzed. Differences in the frequency of ER segments were statistically evaluated using the Wilcoxon signed rank test ( $R$ statistic software). Ultrastructural data were derived from two mice of each genotype.

\section{Acknowledgments}

We are grateful to the expert technical help of A. Ihmer and to the careful animal husbandry of D. Hupfer and F. Neuhalfen. The cDNA array Mouse Unigene Set RZPD 1 (designed by the group of B. Korn, German Resource Center for Genome Research (RZPD), Heidelberg) was produced at RZPD, Berlin (A.Vente, U. Radelof, K. Schäfer). The RNA profilings were performed at RZPD, Heidelberg. We thank C. Rutenberg, S. Wolterink, and F. Schwarz (all RZPD, Heidelberg) for hybridizations and data analysis and members of the lab of A. Poustka at DKFZ (W. Huber, F. Wilmer) for helpful discussions. The work was supported by the BMBF (BMBF 01 KW 9501) to the RZPD and by BONFOR (0-167.0004) to SLB.

\section{Appendix A. Supplementary data}

Supplementary data associated with this article can be found, in the online version, at doi:10.1016/j.mcn.2008.04.010.

\section{References}

Alberi, L., Sgado, P., Simon, H.H., 2004. Engrailed genes are cell-autonomously required to prevent apoptosis in mesencephalic dopaminergic neurons. Development 131 , 3229-3236.

Ashburner, M., Ball, C.A., Blake, J.A., Botstein, D., Butler, H., Cherry, J.M., Davis, A.P. Dolinski, K., Dwight, S.S., Eppig, J.T., Harris, M.A., Hill, D.P., Issel-Tarver, L., Kasarskis, A., Lewis, S., Matese, J.C., Richardson, J.E., Ringwald, M., Rubin, G.M., Sherlock, G., 2000. Gene ontology: tool for the unification of biology. The Gene Ontology Consortium. Nat.Genet. 25, 25-29.

Baader, S.L., Sanlioglu, S., Berrebi, A.S., Parker-Thornburg, J., Oberdick, J., 1998. Ectopic overexpression of Engrailed-2 in cerebellar Purkinje cells causes restricted cell loss and retarded external germinal layer development at lobule junctions. J. Neurosci. $18,1763-1773$. 
Baader, S.L., Vogel, M.W., Zhang, X., Sanlioglu, S., Oberdick, J., 1999. Selective disruption of "late onset" sagittal banding patterns by ectopic expression of Engrailed-2 in cerebellar Purkinje cells. J. Neurosci. 19, 5370-5379.

Bauman, M.L., Kemper, T.L., 2005. Neuroanatomic observations of the brain in autism: review and future directions. Int. J. Dev. Neurosci. 23, 183-187.

Beissbarth, T., Fellenberg, K., Brors, B., rribas-Prat, R., Boer, J., Hauser, N.C., Scheideler, M., Hoheisel, J.D., Schutz, G., Poustka, A., Vingron, M., 2000. Processing and quality control of DNA array hybridization data. Bioinformatics 16, 1014-1022.

Benayed, R., Gharani, N., Rossman, I., Mancuso, V., Lazar, G., Kamdar, S., Bruse, S.E., Tischfield, S., Smith, B.J., Zimmerman, R.A., cicco-Bloom, E., Brzustowicz, L.M., Millonig, J.H., 2005. Support for the homeobox transcription factor gene ENGRAILED 2 as an Autism Spectrum Disorder susceptibility locus. Am. J. Hum. Genet. 77, 851-868.

Black, M.W., Pelham, H.R., 2000. A selective transport route from Golgi to late endosomes that requires the yeast GGA proteins. J. Cell Biol. 151, 587-600.

Boer, J.M., Huber, W.K., Sultmann, H., Wilmer, F., von Heydebreck, A., Haas, S., Korn, B. Gunawan, B., Vente, A., Fuzesi, L., Vingron, M., Poustka, A., 2001. Identification an classification of differentially expressed genes in renal cell carcinoma by expression profiling on a global human 31,500-element cDNA array. Genome Res. 11, 1861-1870.

Bompard, G., Sharp, S.J., Freiss, G., Machesky, L.M., 2005. Involvement of Rac in actin cytoskeleton rearrangements induced by MIM-B. J. Cell Sci. 118, 5393-5403.

Bondy, C.A., Jensen, R.T., Brady, L.S., Gainer, H., 1989. Cholecystokinin evokes secretion of oxytocin and vasopressin from rat neural lobe independent of external calcium. Proc. Natl. Acad. Sci. U. S. A. 86, 5198-5201.

Brazma, A., et al., 2001. Minimum information about a microarray experiment (MIAME)toward standards for microarray data. Nat. Genet. 29, 365-371.

Brunet, I., Weinl, C., Piper, M., Trembleau, A., Volovitch, M., Harris, W., Prochiantz, A. Holt, C., 2005. The transcription factor Engrailed-2 guides retinal axons. Nature 438 94-98.

Celio, M.R., 1990. Calbindin D-28k and parvalbumin in the rat nervous system. Neuroscience 35, 375-475.

Chae, T.H., Kim, S., Marz, K.E., Hanson, P.I., Walsh, C.A., 2004. The hyh mutation uncovers roles for alpha Snap in apical protein localization and control of neural cell fate. Nat. Genet. 36, 264-270.

Cooper, A.A., Gitler, A.D., Cashikar, A., Haynes, C.M., Hill, K.J., Bhullar, B., Liu, K., Xu, K., Strathearn, K.E., Liu, F., Cao, S., Caldwell, K.A., Caldwell, G.A., Marsischky, G. Kolodner, R.D., Labaer, J., Rochet, J.C., Bonini, N.M., Lindquist, S., 2006. Alphasynuclein blocks ER-Golgi traffic and Rab1 rescues neuron loss in Parkinson's models. Science 313, 324-328

Crawley, J.N., Stivers, J.A., Blumstein, L.K., Paul, S.M., 1985. Cholecystokinin potentiates dopamine-mediated behaviors: evidence for modulation specific to a site of coexistence. J. Neurosci. 5, 1972-1983.

Deborde, S., Perret, E., Gravotta, D., Deora, A., Salvarezza, S., Schreiner, R., Redriguez-Boulan, E., 2008. Clathrin is a key regulator of basolateral polarity. Nature 452, 719-725.

Dubreuil, R.R., 2006. Functional links between membrane transport and the spectrin cytoskeleton. J. Membr. Biol. 211, 151-161.

Dvorak, K., Bucek, J., 1970. Postnatal differentiation of the Golgi apparatus and the dendrites of Purkinje cells of the rat cerebellum. A histochemical and electron microscopic study. Z .Zellforsch. Mikrosk. Anat. 111, 51-63.

Ferguson, J.N., Young, L.J., Hearn, E.F., Matzuk, M.M., Insel, T.R., Winslow, J.T., 2000 Social amnesia in mice lacking the oxytocin gene. Nat. Genet. 25, 284-288.

Fischer, M.D., Budak, M.T., Bakay, M., Gorospe, J.R., Kjellgren, D., Pedrosa-Domellof, F. Hoffman, E.P., Khurana, T.S., 2005. Definition of the unique human extraocular muscle allotype by expression profiling. Physiol. Genomics 22, 283-291.

Futerman, A.H., Boldin, S., Brann, A.B., Schwarz, A., Zisling, R., 1998. Regulatory roles for sphingolipids in the growth of polarized neurons. Ann. N. Y. Acad. Sci. 19, 176-187.

Garcia-Frigola, C., Burgaya, F., Calbet, M., De Lecea, L., Soriano, E., 2000. Mouse Tspan-5, a member of the tetraspanin superfamily, is highly expressed in brain cortical structures. Neuroreport 11, 3181-3185.

Gharani, N., Benayed, R., Mancuso, V., Brzustowicz, L.M., Millonig, J.H., 2004. Association of the homeobox transcription factor, ENGRAILED 2, 3, with Autism Spectrum Disorder. Mol. Psychiatry 9, 474-484.

Green, L., Fein, D., Modahl, C., Feinstein, C., Waterhouse, L., Morris, M., 2001. Oxytocin and autistic disorder: alterations in peptide forms. Biol. Psychiatry 50, 609-613.

Harada, A., Furuta, B., Takeuchi, K., Itakura, M., Takahashi, M., Umeda, M., 2000. Nadrin, novel neuron-specific GTPase-activating protein involved in regulated exocytosis. J. Biol. Chem. 275, 36885-36891.

Hashimoto, H., Onaka, T., Kawasaki, M., Chen, L., Mera, T., Soya, A., Saito, T., Fujihara, H. Sei, H., Morita, Y., Ueta, Y., 2005. Effects of cholecystokinin (CCK)-8 on hypothalamic oxytocin-secreting neurons in rats lacking CCK-A receptor. Auton. Neurosci. 121, $16-25$

Hayes, N.V., Scott, C., Heerkens, E., Ohanian, V., Maggs, A.M., Pinder, J.C., Kordeli, E Baines, A.J., 2000. Identification of a novel C-terminal variant of beta II spectrin: two isoforms of beta II spectrin have distinct intracellular locations and activities. J. Cell Sci. 113, 2023-2034

Huber, D., Veinante, P., Stoop, R., 2005. Vasopressin and oxytocin excite distinct neuronal populations in the central amygdala. Science 308, 245-248.

Jankowski, J., Holst, M.I., Liebig, C., Oberdick, J., Baader, S.L., 2004. Engrailed-2 negatively regulates the onset of perinatal Purkinje cell differentiation. J. Comp. Neurol. 472, 87-99.

Juenger, C.H., Holst, M.I., Duffe, K., Jankowski, J., Baader, S.L., 2005. Tetraspanin-5 (Tm4Sf9) mRNA expression parallels neuronal maturation in the cerebellum of normal and L7En-2 transgenic mice. J. Comp. Neurol. 483, 318-328.

Kagami, Y., Furuichi, T., 2001. Investigation of differentially expressed genes during the development of mouse cerebellum. Brain Res.Gene Expr. Patterns 1, 39-59.
Kuemerle, B., Gulden, F., Cherosky, N., Williams, E., Herrup, K., 2006. The mouse Engrailed genes: a window into autism. Behav. Brain Res. 176, 121-132.

Kyuhou, S., Kato, N., Gemba, H., 2006. Emergence of endoplasmic reticulum stress and activated microglia in Purkinje cell degeneration mice. Neurosci. Lett. 396, 91-96.

Landgrebe, J., Wurst, W., Welzl, G., 2002. Permutation-validated principal components analysis of microarray data. Genome Biol. 3, 0019.

Landis, S.C., Mullen, R.J., 1978. The development and degeneration of Purkinje cells in pcd mutant mice. J. Comp. Neurol. 177, 125-143.

Lim, M.M., Bielsky, I.F., Young, L.J., 2005. Neuropeptides and the social brain: potential rodent models of autism. Int. J. Dev. Neurosci. 23, 235-243.

Lin, J., Liu, J., Wang, Y., Zhu, J., Zhou, K., Smith, N., Zhan, X., 2005. Differential regulation of cortactin and N-WASP-mediated actin polymerization by missing in metastasis (MIM) protein. Oncogene. 24, 2059-2066.

Magadan, J.G., Barbieri, M.A., Mesa, R., Stahl, P.D., Mayorga, L.S., 2006. Rab22a regulates the sorting of transferrin to recycling endosomes. Mol. Cell Biol. 26, 2595-2614.

Mainguy, G., Erno, H., Montesinos, M.L., Lesaffre, B., Wurst, W., Volovitch, M., Prochiantz, A., 1999. Regulation of epidermal bullous pemphigoid antigen 1 (BPAG1) synthesis by homeoprotein transcription factors. J. Invest. Dermatol. 113, 643-650.

Mani, M., Lee, S.Y., Lucast, L., Cremona, O., Di, P.G., De, C.P., Ryan, T.A., 2007. The dual phosphatase activity of synaptojanin 1 is required for both efficient synaptic vesicle endocytosis and reavailability at nerve terminals. Neuron 56, 1004-1018.

Mascagni, F., McDonald, A.J., 2003. Immunohistochemical characterization of cholecystokinin containing neurons in the rat basolateral amygdala. Brain Res. 976, 171-184.

Masseroli, M., Martucci, D., Pinciroli, F., 2004. GFINDer: Genome Function INtegrated Discoverer through dynamic annotation, statistical analysis, and mining. Nucleic Acids Res. 32, W293-W300.

Masseroli, M., Galati, O., Pinciroli, F., 2005. GFINDer: genetic disease and phenotype location statistical analysis and mining of dynamically annotated gene lists. Nucleic Acids Res. 33, W717-W723.

Mattila, P.K., Pykalainen, A., Saarikangas, J., Paavilainen, V.O., Vihinen, H., Jokitalo, E., Lappalainen, P., 2007. Missing-in-metastasis and IRSp53 deform PI(4,5)P2-rich membranes by an inverse BAR domain-like mechanism. J. Cell Biol. 176, 953-964.

Miething, A., 2005. Arrested germ cell divisions in the ageing human testis. Andrologia $37,10-16$.

Millen, K.J., Wurst, W., Herrup, K., Joyner, A.L., 1994. Abnormal embryonic cerebellar development and patterning of postnatal foliation in two mouse Engrailed-2 mutants. Development 120, 695-706.

Modahl, C., Green, L., Fein, D., Morris, M., Waterhouse, L., Feinstein, C., Levin, H., 1998. Plasma oxytocin levels in autistic children. Biol. Psychiatry 43, 270-277.

Montesinos, M.L., Foucher, I., Conradt, M., Mainguy, G., Robel, L., Prochiantz, A., Volovitch, M., 2001. The neuronal microtubule-associated protein 1B Is under homeoprotein transcriptional control. J. Neurosci. 21, 3350-3359.

Morata, G., Lawrence, P.A., 1975. Control of compartment development by engrailed gene in Drosophila. Nature 255, 614-617.

Mutch, D.M., Berger, A., Mansourian, R., Rytz, A., Roberts, M.A., 2002. The limit fold change model: a practical approach for selecting differentially expressed genes from microarray data. Bioinformatics 3, 17.

Palmen, S.J., van Engeland, H., Hof, P.R., Schmitz, C., 2004. Neuropathological findings in autism. Brain 127, 2572-2583.

Phillips, S.A., Barr, V.A., Haft, D.H., Taylor, S.I., Haft, C.R., 2001. Identification and characterization of SNX15, a novel sorting nexin involved in protein trafficking. J. Biol. Chem. 276, 5074-5084.

Qin, B., He, M., Chen, X., Pei, D., 2006. Sorting nexin 10 induces giant vacuoles in mammalian cells. J. Biol. Chem. 281, 36891-36896

Quackenbush, J., 2001. Computational analysis of microarray data. Nat. Rev. Genet. 2, 418-427.

Ritvo, E.R., Freeman, B.J., Scheibel, A.B., Duong, T., Robinson, H., Guthrie, D., Ritvo, A., 1986. Lower Purkinje cell counts in the cerebella of four autistic subjects: initial findings of the UCLA-NSAC Autopsy Research Report. Am. J. Psychiatry 143, $862-866$

Sanlioglu, S., Zhang, X., Baader, S.L., Oberdick, J., 1998. Regulation of a Purkinje cellspecific promoter by homeobox proteins: repression by Engrailed-2 vs. synergistic activation by HoxA5 and HoxB7. J. Neurobiol. 36, 559-571.

Sato, M., Suzuki, K., Yamazaki, H., Nakanishi, S., 2005. A pivotal role of calcineurin signaling in development and maturation of postnatal cerebellar granule cells. Proc. Natl. Acad. Sci. U. S. A. 102, 5874-5879.

Schaefer, G.B., Thompson, J.N., Bodensteiner, J.B., McConnell, J.M., Kimberling, W.J., Gay, C.T., Dutton, W.D., Hutchings, D.C., Gray, S.B., 1996. Hypoplasia of the cerebellar vermis in neurogenetic syndromes. Ann. Neurol. 39, 382-385.

Schulkin, J., 2007. Autism and the amydala: an endocrine hypothesis. Brain Cogn. 65 , 87-99.

Serrano, N., Brock, H.W., Demeret, C., Dura, J.M., Randsholt, N.B., Kornberg, T.B., Maschat, F., 1995. Polyhomeotic appears to be a target of engrailed regulation in Drosophila. Development 121, 1691-1703.

Serrano, N., Brock, H.W., Maschat, F., 1997. alpha3-Tubulin is directly repressed by the Engrailed protein in Drosophila. Development 124, 2527-2536.

Sgaier, S.K., Lao, Z., Villanueva, M.P., Berenshteyn, F., Stephen, D., Turnbull, R.K., Joyner, A.L., 2007. Genetic subdivision of the tectum and cerebellum into functionally related regions based on differential sensitivity to engrailed proteins. Development 134, 2325-2335.

Shestakova, A., Suvorova, E., Pavliv, O., Khaidakova, G., Lupashin, V., 2007. Interaction of the conserved oligomeric Golgi complex with t-SNARE Syntaxin5a/Sed5 enhances intra-Golgi SNARE complex stability. J. Cell Biol. 179, 1179-1192.

Siegler, M.V.S., Jia, X.X., 1999. Engrailed negatively regulates the expression of cell adhesion molecules connectin and neuroglian in embryonic Drosophila nervous system. Neuron 22, 265-276. 
Simon, H.H., Scholz, C., O'Leary, D.D., 2005. Engrailed genes control developmental fate of serotonergic and noradrenergic neurons in mid- and hindbrain in a gene dosedependent manner. Mol.Cell Neurosci. 28, 96-105.

Simpson, J.C., Griffiths, G., Wessling-Resnick, M., Fransen, J.A., Bennett, H., Jones, A.T., 2004. A role for the small GTPase Rab21 in the early endocytic pathway. J. Cell Sci. 117, 6297-6311.

Tabuchi, K., Blundell, J., Etherton, M.R., Hammer, R.E., Liu, X., Powell, C.M., Sudhof, T.C., 2007. A neuroligin-3 mutation implicated in autism increases inhibitory synaptic transmission in mice. Science 318, 71-76.

Tolkunova, E.N., Fujioka, M., Kobayashi, M., Deka, D., Jaynes, J.B., 1998. Two distinct types of repression domain in engrailed: one interacts with the groucho corepressor and is preferentially active on integrated target genes. Mol. Cell Biol. 18, 2804-2814.

Tusher, V.G., Tibshirani, R., Chu, G., 2001. Significance analysis of microarrays applied to the ionizing radiation response. Proc. Natl. Acad. Sci. U. S. A. 98, 5116-5121.
Winslow, J.T., Insel, T.R., 2002. The social deficits of the oxytocin knockout mouse Neuropeptides 36, 221-229.

Wyszynski, M., Kharazia, V., Shanghvi, R., Rao, A., Beggs, A.H., Craig, A.M., Weinberg, R. Sheng, M., 1998. Differential regional expression and ultrastructural localization of alpha-actinin-2, a putative NMDA receptor-anchoring protein, in rat brain. J. Neurosci. $18,1383-1392$

Yang, Y.H., Speed, T., 2002. Design issues for cDNA microarray experiments. Nat. Rev. Genet. 3, 579-588.

Ye, B., Zhang, Y., Song, W., Younger, S.H., Jan, L.Y., Jan, Y.N., 2007. Growing dendrites and axons differ in their reliance on the secretory pathway. Cell 130, 717-729.

Zhang, J.Z., Davletov, B.A., Sudhof, T.C., Anderson, R.G., 1994. Synaptotagmin I is a high affinity receptor for clathrin AP-2: implications for membrane recycling. Cell 78, 751-760.

Zhao, L., Longo-Guess, C., Harris, B.S., Lee, J.W., Ackerman, S.L., 2005. Protein accumulation and neurodegeneration in the woozy mutant mouse is caused by disruption of SIL1, a cochaperone of BiP. Nat. Genet. 37, 974-979. 